\title{
Fusarium Head Blight of Cultivated and Natural Wild Rice (Zizania palustris) in Minnesota Caused by Fusarium graminearum and Associated Fusarium spp.
}

\author{
R. F. Nyvall, Professor, University of Minnesota, North Central Experiment Station, Grand Rapids 55744; J. A. \\ Percich, Professor, and C. J. Mirocha, Professor Emeritus, Department of Plant Pathology, University of Minne- \\ sota, St. Paul 55108
}

\begin{abstract}
Nyvall, R. F., Percich, J. A., and Mirocha, C. J. 1999. Fusarium head blight of cultivated and natural wild rice (Zizania palustris) in Minnesota caused by Fusarium graminearum and associated Fusarium spp. Plant Dis. 83:159-164.

Symptoms of Fusarium head blight on diseased wild rice seed from both cultivated fields and natural stands are shrunken, light weight seeds discolored light tan to light brown with infrequent light pink due to mycelial growth of Fusarium spp. F. graminearum was the predominant species isolated from whole seed at all growth stages, and from shattered seed gathered from four fields in 1994 to 1995. F. anthophilum and F. subglutinans were also frequently isolated at most growth stages, whereas F. acuminatum, F. culmorum, F. solani, and F. semitectum were infrequently isolated at one or more growth stages, and $F$. camptoceras was isolated only from shattered seed. F. graminearum was the only species isolated from processed seed, although rarely. Fusarium spp. were isolated at the highest percentage from shattered seed. The highest percentage of total Fusarium spp. isolated during seed development was at the milk and dough stages in a cultivated field and at the milk stage in a natural stand; the percentage then declined until the ripe stage in seed from both sites. There were no significant differences in the percentages of Fusarium spp. isolated at growth stages between seed from the cultivated field and from the natural stand. Fusarium spp. were isolated most frequently from whole seed grown in three cultivated fields, compared with the palea and lemma, and caryopsis. F. graminearum and $F$. anthophilum were frequently isolated from whole seed and all seed structures, whereas $F$. culmorum and $F$. sporotrichioides were isolated only from whole seed, F. moniliforme from whole seed, palea and lemma, and caryopsis, and F. subglutinans from whole seed and the palea and lemma only. Deoxynivalenol and nivalenol were identified in three isolates of $F$. graminearum; however, none of the seed samples from which the isolates were obtained yielded either mycotoxin. Survival of Fusarium spp. in diseased seed was similar from both cultivated and natural sources and occurs in whole seed not immersed in water but not in seed immersed in water. Survival was better in seed stored at $4^{\circ} \mathrm{C}$ than at $-20^{\circ} \mathrm{C}$. F. graminearum was reisolated from $81 \%$ of seed from inoculated plants but not from seed of noninoculated plants. Pathogenicity of other Fusarium spp. remains to be demonstrated.
\end{abstract}

Cultivated wild rice (Zizania palustris) is grown on approximately 6,882 ha in Minnesota while natural stands of wild rice are common in lakes and rivers throughout northern Minnesota. The Minnesota Cultivated Wild Rice Council estimates the growth and sale of wild rice contributes over $\$ 41.6$ million to the state's economy (Minnesota Cultivated Wild Rice Council, personal communication). Diseases have been an important factor in the cultivation of wild rice since 1961 (2). Most research

Corresponding author: Robert F. Nyvall E-mail: nyval001@tc.umn.edu

Published as paper no. 981220043 of the contribution series of the Minnesota Agricultural Experiment Station based on research conducted under Project 22-68. University of Minnesota Experiment Station number 981220043.

Accepted for publication 6 November 1998.

Publication no. D-1998-1210-01R

(C) 1999 The American Phytopathological Society efforts have concentrated on fungal brown spot (Bipolaris oryzae), which is considered to be the most severe disease of cultivated wild rice in Minnesota $(5,11,12)$, causing average annual losses estimated at $\$ 2.5$ million. Depending upon disease severity, losses in individual fields can vary from slight to $75 \%(2,6,7)$ with anecdotal evidence ascribing losses of $100 \%$ in fields where disease was especially severe.

Fusarium head blight caused by Fusarium spp. is a widespread disease that affects most small grains. During 1993, a severe Fusarium head blight epiphytotic caused extensive damage to the wheat crop throughout the Red River Valley of northwestern Minnesota and northeastern North Dakota (8). However, Fusarium head blight was previously not known to affect cultivated wild rice nor was it known to affect natural stands of wild rice $(10,13)$.

During the autumn of 1993, samples of wild rice seed ( 20 to $21 \%$ moisture), either immediately frozen or stored at room temperature in the laboratory for several days after harvest, were observed to be shrunken, discolored light tan to light brown, and colonized by pinkish to red mycelium. Fusarium spp. were isolated from symptomatic kernels stored in both conditions.

The high humidity that occurs in both cultivated and natural stands of wild rice is optimal for Fusarium head blight development. Diseased grain may contain mycotoxins that induce muscle spasms and vomiting in humans and other nonruminant animals. The toxins apparently remain stable for 7 months in stored grain (3). Bread made from scabby wheat has been described as "intoxicating" (16). Since cultivated and naturally grown wild rice are becoming widely used either alone or in mixtures with other food stuffs throughout Canada and the United States, infection by Fusarium spp. may potentially represent another mode by which harmful toxins can be introduced into the human food chain.

Investigations were undertaken to determine (i) symptoms of Fusarium head blight on wild rice seed, (ii) incidence and identity of Fusarium spp. in cultivated and natural stands of wild rice, (iii) relationship of Fusarium spp. infection to seed development and seed structures, (iv) effect of storage conditions on survival of Fusarium spp. in seed, (v) presence of mycotoxins in $F$. graminearum cultures and seed from which they were obtained, and (vi) completion of Koch's postulates with $F$. graminearum. To our knowledge, this is the first report of Fusarium head blight on either cultivated or natural wild rice. A preliminary report on Fusarium head blight (scab) of cultivated wild rice has been published (13).

\section{MATERIALS AND METHODS}

Isolation from seed and identification of Fusarium spp. Fusarium spp. were isolated from seed in all experiments by the following procedure. Whole seeds were surface treated by washing in running tap water at $7^{\circ} \mathrm{C}$ for $30 \mathrm{~min}$, placed in a $1: 1$ solution ( $\mathrm{vol} / \mathrm{vol})$ of $1 \%$ sodium hypochlorite $(\mathrm{NaOCl})$ and $75 \%$ ethanol (ETOH) for $3 \mathrm{~min}$, rinsed twice in sterile, distilled water (SDW), and placed on potato dextrose agar adjusted to $\mathrm{pH} 4.5$ with $50 \%$ lactic acid (APDA).

Isolation from the palea and lemma, and caryopsis, was done by washing whole seeds in running tap water for $2 \mathrm{~h}$. The longer washing time facilitated an easier 
separation of the palea and lemma from the caryopsis with forceps than did the $30 \mathrm{~min}$ washing times. The palea and lemma were surface treated in the 1:1 NaOCl:ETOH solution for $30 \mathrm{~s}$, rinsed twice in SDW, and placed on APDA. The caryopsis was surface treated for $1 \mathrm{~min}$, rinsed twice in SDW, and placed on APDA.

Whole seeds, palea and lemma, and caryopsis were incubated at 22 to $26^{\circ} \mathrm{C}$ under cool, white fluorescent lights and, after 7 days of growth, were exposed for the next 7 days to UV light $(360 \mathrm{~nm})$ for $30 \mathrm{~min}$ daily to enhance sporulation. Some cultures were exposed to UV light (24 $\min / 24 \mathrm{~h}$ ) for an additional 7 days.

Fusarium cultures were identified to species after 14 to 21 days with the key by Nelson et al. (10). Cultures not immediately identified were placed on APDA slants and identified when convenient. Final identification of these cultures was made by growing a culture, started from a single spore, either on carnation leaf agar or potassium chloride (KCL) medium under available fluorescent lights at 22 to $26^{\circ} \mathrm{C}$. Occasionally, cultures that did not sporulate after 14 days were placed under UV light $(360 \mathrm{~nm})$ for 0.5 to $2.0 \mathrm{~h}$ for 7 days. Again, these cultures were identified with the key by Nelson et al. Identification of fungi other than Fusarium spp. was done with the key by Barnett (1).

Symptoms of Fusarium head blight on wild rice seed. Five hundred symptomatic and asymptomatic seeds were gathered from each of two cultivated wild rice fields and two natural wild rice sources for a total of 1,000 seeds/symptom/source. Isolations were made to confirm the presence of Fusarium spp. All Fusarium isolates were identified to species. Criteria for symptoms considered typical of Fusarium

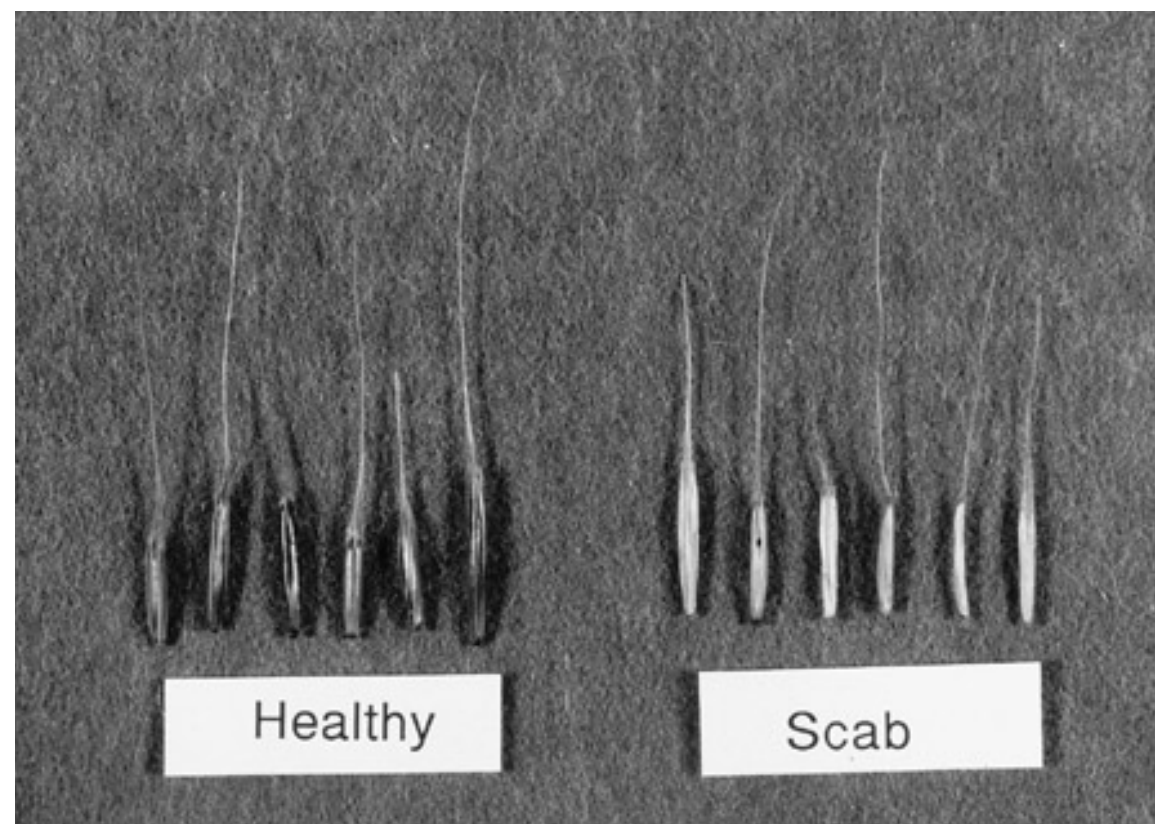

Fig. 1. Symptoms of Fusarium head blight on naturally diseased wild rice seed (right), compared with healthy wild rice seed (left).

head blight were light tan, light brown, bleached, or otherwise discolored and shrunken seed (Fig. 1).

Comparison of Fusarium spp. isolated from cultivated wild rice seed at the milk, dough, and ripe stages of development, and from shattered seed. The milk, dough, and ripe stages of seed development were based on the criteria by Percich et al. (15). In this experiment, the milk stage refers to medium milk, dough to hard dough, and ripe to the vascular strand collapsed on half of the seeds. These growth stage criteria are used in all subsequent experiment descriptions. Shattered seed refers to ripe seed that has been shed from the plant and fallen to the soil surface before harvest. The term "shattering" will be used in this context throughout the paper. Processing refers to placing seed at approximately $94^{\circ} \mathrm{C}$ for $90 \mathrm{~min}$ then increasing the temperature to 117 to $120^{\circ} \mathrm{C}$ for $30 \mathrm{~min}$, after which the heating is stopped and seed is allowed to cool to ambient temperature.

Four fields were selected in 1994 and 1995 that represented the major cultivated wild rice-growing areas in Minnesota. The cultivar Franklin was grown in two fields and the cultivar K-2 in the other two. In each field, five sampling sites (20 m apart) were arranged in a circular pattern beginning approximately $100 \mathrm{~m}$ from the field edge. Sampling was considered as a simple binomial distribution.

At each growth stage, the seed heads of five plants, randomly selected from each sampling site, were hand harvested. All seed from the five sampling sites within a field was bulked and 300 seeds were randomly selected for fungal isolation. Shattered seed was collected in five plastic trays $(17 \times 28 \mathrm{~cm})$ placed on the soil sur-

160 Plant Disease/Vol. 83 No. 2 face at each sampling site beginning at the milk stage of seed development. Five bags, each from a separate, unknown, cultivated wild rice field and containing $1 \mathrm{~kg}$ of processed wild rice seed grown that year, were obtained from a food store, the seed was bulked, and 1,200 seeds were randomly selected each year for fungal isolation.

The results between fields and years did not vary significantly. Therefore, the isolation results from the four fields and processed seed were combined for both years and are based on a total of 2,400 seeds per growth stage, shattered, and processed. All Fusarium isolates were identified to species.

Comparison between percentages of Fusarium spp. isolated from seed at different growth stages from a cultivated field and a natural stand. Seed of cultivar $\mathrm{K}-2$ grown in a field $14 \mathrm{~km}$ north of Clearwater, $\mathrm{MN}$, and from a natural stand of wild rice located in the Moose River 18 $\mathrm{km}$ from Hill City, MN, was harvested at the milk, dough, and ripe stages in 1994 and 1995. Although the distance separating the cultivated field and natural stand was approximately $200 \mathrm{~km}$, the development of seed from a natural stand occurs at widely variant times within the stand, compared with the relatively uniform development of seed within a cultivated stand. Therefore, it was deemed more important to acquire seed from natural sources at the growth stage comparable to cultivated wild rice regardless of the distance separating the stands, assuming primary inoculum and environmental conditions favorable for disease development were similar.

Seed in the cultivated field was gathered at each growth stage from five sites within the field, $20 \mathrm{~m}$ apart, and bulked, and 450 seeds were randomly selected for isolation. Seed-bearing plants from the Moose River were not growing in uniform stands and tended to be in different stages of development. Thus, seed was gathered from plants at several different sites but within the same general locality at each growth stage and bulked, and 450 seeds were randomly selected for isolation. Sampling was considered as a simple binomial distribution. Fusarium isolates were not identified to species.

The results between fields and years did not vary significantly. Therefore, the isolation results were combined for 1994 and 1995. Thus, each percentage is based on the isolations from 900 seeds.

Comparison of Fusarium spp. isolated from palea and lemma, caryopsis, and whole seed grown in three cultivated fields. Three fields in 1994 and 1995 were selected in which the cultivar Franklin was grown. Ripe seed was harvested from five sampling sites in each field that were arranged in a pattern as previously described. Sampling was considered as a simple binomial distribution. Seed from each field was bulked and isolations were made from 
300 whole seeds, 100 palea and lemma, and 100 caryopsis. Results of the three fields from both years were combined and are based on a total of 600 palea and lemma, 600 caryopsis, and 1,800 whole seeds.

Isolation of Fusarium spp. from seed grown in a cultivated field and a natural stand. The result from the previous experiment was not applicable because it was a compilation of three fields that were considered to differ environmentally from any known natural stand. In this experiment, the cultivated wild rice field was located $14 \mathrm{~km}$ north of Aitkin, $\mathrm{MN}$, and the natural seed source was from the Moose River located approximately $30 \mathrm{~km}$ distant. Although the primary inoculum sources are presumed to differ, the environmental conditions, consisting of rainfall and ambient temperature, would be similar. Total rainfall and temperature were measured weekly from flowering to maturity at 1.75 and $1.00 \mathrm{~m}$, the approximate height of the seed heads grown in the cultivated field and natural stand, respectively. Seed was gathered in the same manner at stages of development as previously described. Seed was bulked and isolations were made from 450 whole seed and 150 seed separated into the palea and lemma, and caryopsis, as previously described. All Fusarium isolates were identified to species.

Results are the combined data from 1994 and 1995. Thus, each percentage is based on isolations from 900 whole seeds, 300 palea and lemma, and 300 caryopsis. The experimental design was a set sampling based on a simple binomial distribution.

Analysis for deoxynivalenol and nivalenol. Three cultures of $F$. graminearum, and the seed sources from which they were isolated, were tested for the presence of deoxynivalenol and nivalenol. One culture was isolated from seed gathered from a wild rice stand in Dora Lake in north central Minnesota and two cultures were isolated from seed grown in cultivated wild rice fields near Clearwater, $\mathrm{MN}$, and Aitkin, MN, respectively. The cultures from the three locations were each ground in a mill for $1 \mathrm{~min}$, placed in a flask to which extraction solvent (acetonitrile:water, 84: $16 \mathrm{vol} / \mathrm{vol}$ ) was added, and shaken for $1 \mathrm{~h}$. The extract was filtered through Whatman \#4 filter paper and added to a charcoal column previously activated with extraction solvent. The eluate was evaporated to dryness and analyzed by high-pressure liquid chromatography at $229 \mathrm{~nm}$ (Shimadzu SLC-6A; Tokyo). A similar procedure was done to the seed from which the cultures were isolated, to determine the presence of deoxynivalenol and nivalenol.

Effect of seed source and storage conditions on the isolation of fusaria from whole seed. Wild rice seed to be sown the following year is normally stored submerged in water either outside or in un- heated facilities during the winter. Ripe wild rice seed was obtained from a natural stand in Dora Lake in north central Minnesota and from a field of cultivated wild rice (cultivar K-2) located $14 \mathrm{~km}$ north of Clearbrook, MN, in 1994 and 1995. Seed was chosen from areas within each site that had an apparently high incidence of disease. No attempt was made to separate symptomatic from asymptomatic seed.

Seed was either dried to 20 to $21 \%$ moisture or immersed in water after harvest, and then subsamples were stored at either $4^{\circ} \mathrm{C}$ or $-20^{\circ} \mathrm{C}$ for 5 months. At the end of the storage time, 500 seeds per treatment were randomly selected for fungal isolation as previously described. An additional 500 seeds that had been immersed in water were placed on pentachloronitrobenzene (PCNB) agar, adjusted to $\mathrm{pH} 4.5$ to 5.0 with $50 \%$ lactic acid to determine if other fungal growth was masking development of fusaria. Results are the combined data from 1994 and 1995. Thus, each percentage is based on isolations from 1,000 seeds. No attempt was made, in this experiment, to identify Fusarium isolates to species. Experimental design was a paired sample.

Effect of storage temperature on the isolation of fusaria from whole seed, palea and lemma, and caryopsis of wild rice seed from a natural and a cultivated source. The purpose was to assess the survival of fusaria in seed and seed structures from a cultivated and a natural stand. The cultivated wild rice field and the natural wild rice stand were approximately $30 \mathrm{~km}$ apart. Seed, grown in 1994 and 1995, was gathered from a field of cultivated wild rice $10 \mathrm{~km}$ from Aitkin, $\mathrm{MN}$, and from a site in the Moose River approximately 30 $\mathrm{km}$ from the cultivated site, then dried to 20 to $21 \%$ moisture for 3 days on a laboratory bench. Seed was chosen from areas within each site that had an apparently high incidence of disease. Symptomatic and asymptomatic seeds were not separated. Subsamples were stored at either $4^{\circ} \mathrm{C}$ or $-20^{\circ} \mathrm{C}$ for 5 months.

At the end of the storage period, seeds were placed at room temperature for 1 day and isolations done as previously described. In this experiment, isolations were made from 300 whole seeds, 100 palea and lemma, and 100 caryopsis in each year. Results are the combined data from both years. Experimental design was a paired sample. No attempt was made, in this experiment, to identify Fusarium isolates to species.

Recovery of $\boldsymbol{F}$. graminearum from inoculated or uninoculated wild rice seed. Koch's postulates were fulfilled by selecting a culture of $F$. graminearum and inoculating 100 cultivated wild plants growing in the greenhouse. Plants were grown in $20-\mathrm{cm}$ plastic pots (two plants per pot) submerged in water to a depth of 5 to $8 \mathrm{~cm}$ above the pot. Supplemental light was from white fluorescent light $\left(84 \mu \mathrm{E} \mathrm{s}^{-1} \mathrm{~m}^{-2}\right.$ measured at the top of the foliage) for $12 \mathrm{~h}$ per day. Temperature varied between 19 to $22^{\circ} \mathrm{C}$ and 18 to $19^{\circ} \mathrm{C}$, day and night, respectively. Inoculum of $F$. graminearum was grown on APDA for the first 14 days under available laboratory light and, for the final 7 days, was exposed to UV light (360 $\mathrm{nm}$ ) for $30 \mathrm{~min}$ daily to enhance sporulation. Macroconidia were harvested by rinsing cultures with SDW loosened with a sterile glass rod. The resulting inoculum was adjusted to $2 \times 10^{4}$ macroconidia per $\mathrm{ml}$ in SDW and Tween 20 (0.2 ml/liter) and applied to plants until runoff at the milk stage. Plants were not covered after inoculation. Tween 20 and SDW were applied to control plants until runoff. Inoculated and control plants were randomized as a single factor experiment in a complete block design. At the ripe stage, 150 seeds were randomly chosen from the inoculated and control treatments, each without regard to symptoms. The experiment was done once.

Statistics. Data were first subjected to analysis of variance. Mean separations were done with Duncan's $t$ test $(P=0.05)$, with Statview version 4.02 (Abacus Concepts, Berkeley, CA).

\section{RESULTS}

Symptoms of Fusarium head blight on wild rice seed. Fusarium head blight symptoms on wild rice have not been previously described but are similar to those of other small grains. Healthy wild rice seed is typically a "full" elongated seed with a color described as varying from purplish-black to dark brown or greenishbrown. Symptoms of Fusarium head blight on diseased wild rice seed from both cultivated fields and natural stands are shrunken, light-weight seeds with a light tan to light brown discoloration (Fig. 1). Infrequently, seeds have a light pink discoloration due to mycelial growth of Fusarium spp. under warm, humid conditions. Symptoms of Fusarium head blight on inoculated plants are similar to those in the field.

Fusarium spp. were isolated from 100 and $98 \%$ of symptomatic and 15 and $11 \%$ of asymptomatic seeds, from cultivated and natural sources, respectively. The Fusarium spp. isolated from seed from both cultivated and natural sources were $F$. anthophilum, $F$. culmorum, $F$. graminearum, $F$. semitectum, and $F$. subglutinans $(39,8,47,3,3$, and $34,13,43,4,6 \%$, respectively). Only $F$. graminearum was isolated from asymptomatic seed, regardless of source.

Comparison of Fusarium spp. isolated from cultivated wild rice seed at the milk, dough, and ripe stages of development, and from shattered seed. $F$. graminearum was the predominant Fusarium $\mathrm{sp}$. isolated from cultivated wild rice 
(Table 1). The fungus was detected at all growth stages, and from shattered seed, and was the only Fusarium sp. isolated from processed seed $(0.6 \%)$. F anthophilum was frequently isolated at all growth stages and from shattered seed. F. anthophilum previously had rarely been isolated from cereals. On APDA, F. anthophilum cultures resembled $F$. oxysporum; therefore, identification was done on KCL media. The distinguishing characteristic on mycelium. Macroconidia are abundant on KCL media and are straight to slightly sickle-shaped with a foot-shaped basal cell. The most distinguishing characteristic on KCL media was oval, globose or pearshaped microconidia borne in false heads on polyphialides and occasionally on monophialides. Most cultures from wild rice produced pear-shaped microconidia.

$F$. subglutinans was isolated in lesser amounts from all growth stages, except the dough stage, and from shattered seed. $F$. culmorum, F. acuminatum, F. solani, and $F$. semitectum were isolated at levels below $1 \%$ from growth stages and shattered seed. $F$. camptoceras was isolated only from shattered seed, at less than $1 \%$ (Table 1).

There was a significant difference between the percentages of total Fusarium spp. isolated from seed at different growth stages, compared with ripe seed retained APDA was rapidly growing, white aerial

on the plant (Table 1). The largest percentage of total Fusarium spp. was isolated at the milk stage of seed development (39.8\%). The percentage of isolations then declined sharply at the dough stage $(6.7 \%)$ and continued to decline until the ripe stage (1.7\%). Fusarium spp. were isolated at the highest percentage from shattered seed $(63.6 \%)$.

Comparison between percentages of Fusarium spp. isolated from seed at different growth stages from a cultivated field and a natural stand. There were no significant differences in the percentages of Fusarium spp. isolated at the milk, dough, or ripe growth stages between the cultivated field $(7,7$, and $2 \%$, respectively) and the natural stand $(10,5$, and $2 \%$, respectively).

Comparison of Fusarium spp. isolated from palea and lemma, caryopsis, and whole seed grown in three cultivated fields. Fusarium spp. were isolated most frequently from whole seed, compared with palea and lemma, and caryopsis (65, 36 , and $26 \%$, respectively), (Table 2 ). $F$. graminearum and $F$. anthophilum were isolated in the greatest incidence from whole seed, and palea and lemma; however, F. graminearum was significantly more common in the caryopsis. F. culmorum, F. moniliforme, F. sporotrichioides, and $F$. subglutinans were infrequently iso-

Table 1. Comparison of Fusarium spp. isolated from cultivated wild rice seed at the milk, dough, and ripe stages of development, and from shattered seed

\begin{tabular}{lcccc}
\hline & \multicolumn{3}{c}{ Growth stage $^{\mathbf{y}}$} & \\
\cline { 2 - 4 } Fusarium spp. & Milk (\%) & Dough (\%) & Ripe (\%) & Shattered (\%) \\
\hline F. acuminatum & $0.0 \mathrm{a}$ & $0.1 \mathrm{a}$ & $0.0 \mathrm{a}$ & 0.1 \\
F. anthophilum & $14.5 \mathrm{~b}$ & $2.0 \mathrm{a}$ & $0.6 \mathrm{a}$ & $21.2 \mathrm{~b}$ \\
F. camptoceras & $0.0 \mathrm{a}$ & $0.0 \mathrm{a}$ & $0.0 \mathrm{a}$ & $0.1 \mathrm{a}$ \\
F. culmorum & $0.1 \mathrm{a}$ & $0.1 \mathrm{a}$ & $0.1 \mathrm{a}$ & $0.5 \mathrm{a}$ \\
F. graminearum & $21.8 \mathrm{~b}$ & $4.5 \mathrm{c}$ & $0.5 \mathrm{~b}$ & $34.2 \mathrm{~b}$ \\
F. semitectum & $0.1 \mathrm{a}$ & $0.0 \mathrm{a}$ & $0.0 \mathrm{a}$ & $0.1 \mathrm{a}$ \\
F. solani & $0.0 \mathrm{a}$ & $0.0 \mathrm{a}$ & $0.1 \mathrm{a}$ & $0.8 \mathrm{a}$ \\
F. subglutinans & $3.4 \mathrm{c}$ & $0.0 \mathrm{a}$ & $0.4 \mathrm{a}$ & $6.7 \mathrm{c}$ \\
\hline
\end{tabular}

${ }^{y}$ Seeds were collected at approximate medium milk and soft dough. Ripe refers to vascular strand collapsed on half of seeds. Shattered refers to seed fallen to ground and collected in plastic trays.

${ }^{\mathrm{z}}$ Percentage is based on 300 seeds from each of four locations per growth stage per year for a total of 2,400 seeds per growth stage. Ratings followed by the same letter within columns only or across the entire table are not significantly different $(P=0.05)$.

Table 2. Comparison of Fusarium spp. isolated from palea and lemma, caryopsis, and whole seed grown in three cultivated fields

\begin{tabular}{lccc}
\hline & \multicolumn{3}{c}{ Seed structure } \\
\cline { 2 - 4 } Fusarium spp. & Whole seed $(\%)^{\mathbf{z}}$ & Palea and lemma (\%) & Caryopsis (\%) \\
\hline F. anthophilum & $27 \mathrm{a}$ & $16 \mathrm{~b}$ & $3 \mathrm{c}$ \\
F. culmorum & $1 \mathrm{c}$ & $0 \mathrm{c}$ & $0 \mathrm{c}$ \\
F. graminearum & $34 \mathrm{a}$ & $18 \mathrm{~b}$ & $22 \mathrm{~b}$ \\
F. moniliforme & $2 \mathrm{c}$ & $1 \mathrm{c}$ & $1 \mathrm{c}$ \\
F. sporotrichioides & $1 \mathrm{c}$ & $0 \mathrm{c}$ & $0 \mathrm{c}$ \\
F. subglutinans & $1 \mathrm{c}$ & $1 \mathrm{c}$ & $0 \mathrm{c}$ \\
Total & $65 \mathrm{e}$ & $36 \mathrm{~d}$ & $26 \mathrm{a}$ \\
\hline
\end{tabular}

${ }^{\mathrm{z}}$ Each percentage is based on a total of 1,800 whole seeds, 600 palea and lemma, and 600 caryopsis. Three hundred whole seeds, 100 palea and lemma, and 100 caryopsis were gathered from each of three wild rice fields per year and bulked together for a total of 900 whole seeds, 300 palea and lemma, and 300 caryopsis each year. Ratings followed by the same letter are not significantly different $(P=0.05)$. lated $(1,2,1$, and $2 \%$, respectively). There was no significant difference $(P=0.05)$ between incidence of isolation of $F$. graminearum from the palea and lemma and from the caryopsis, but there was a significant difference from incidence of isolation from whole seed. In contrast, the incidence of $F$. anthophilum was significantly different for all three. F. culmorum and $F$. sporotrichioides were isolated only from whole seed, whereas $F$. moniliforme was isolated from whole seed, palea and lemma, and caryopsis, and $F$. subglutinans was isolated from whole seed and the palea and lemma only.

Isolation of Fusarium spp. from seed grown in a cultivated field and a natural stand. Temperature and rainfall were the same at both sites. F. graminearum was the species most frequently isolated from whole wild rice seed (58 and 59\%), palea and lemma (48 and 33\%), and caryopsis (45 and 19\%) from the cultivated field and natural stand, respectively. There was no significant difference in the percentage of other Fusarium spp. isolated from whole seed, including $F$. anthophilum (1 and $0 \%$ ), F. culmorum (1 and 0\%), F. moniliforme (2 and $1 \%), F$. sporotrichioides (1 and $0 \%$ ), and $F$. subglutinans ( 1 and $0 \%$ ) from the cultivated field and natural stand, respectively. F. moniliforme was the only other species isolated from the palea and lemma and from the caryopsis of seed from both sources (1\% each).

Analysis for deoxynivalenol and nivalenol. Deoxynivalenol and nivalenol were identified in all three $F$. graminearum isolates. The isolate from Dora Lake contained 12.67 and $18.15 \mu \mathrm{g}$ of deoxynivalenol and nivalenol per $\mathrm{ml}$, respectively. The isolates from Clearwater and Aitkin contained 3.14 and $68.73 \mu \mathrm{g}$ of deoxynivalenol per ml, respectively, and 0.10 and $18.27 \mu \mathrm{g}$ of nivalenol per ml, respectively. None of the three seed samples from which the isolates were obtained (100\% infested with F. graminearum) yielded either mycotoxin.

Effect of seed source and storage conditions on the isolation of fusaria from whole seed. There was no significant difference $(P=0.05)$ between the cultivated and natural sources in survival of fusaria in diseased seed (Table 3). The highest survival percentage occurred in seed at $4{ }^{\circ} \mathrm{C}$ not immersed in water (81 and $64 \%$, cultivated and natural source, respectively). No survival occurred in seed immersed in water at $4^{\circ} \mathrm{C}$. However, fusaria were isolated from seed immersed in water at $-20^{\circ} \mathrm{C}(12$ and $14 \%$, cultivated and natural source, respectively). A Mucor sp., a Geotrichum sp., and Saccharomyces spp. were consistently isolated from all seed samples immersed in water. The growth of these fungi did not mask the development of fusaria.

Effect of storage temperature on the isolation of fusaria from whole seed, palea and lemma, and caryopsis of wild rice seed from a natural and a cultivated 
source. Survival of fusaria was highest in whole seed for all source/temperature combinations except cultivated seed at $4^{\circ} \mathrm{C}$ (Table 4). There was no significant difference $(P=0.05)$ in survival of fusaria between cultivated whole seed, palea and lemma, and caryopsis. However, fusaria survived at a significantly higher percentage in whole seed from the natural source, compared with the palea and lemma, and the caryopsis.

There was no significant difference in the survival of fusaria in whole seed between $-20^{\circ} \mathrm{C}$ and $4^{\circ} \mathrm{C}$, regardless of source. However, there was significantly less survival at $-20^{\circ} \mathrm{C}$ than at $4^{\circ} \mathrm{C}$ in the caryopsis regardless of source, and in the palea and lemma from the cultivated but not the natural source. At $-20^{\circ} \mathrm{C}$, there was no significant difference in fusaria survival in either the palea and lemma, or caryopsis, regardless of source.

Reisolation of $\boldsymbol{F}$. graminearum from inoculated and noninoculated wild rice seed. $F$. graminearum was reisolated from $81 \%$ of seed from inoculated plants but was not isolated from seed of noninoculated plants.

\section{DISCUSSION}

Fusarium head blight was identified as a newly discovered disease of wild rice in 1995 (13). High relative humidity that favors the development of Fusarium head blight on small grains is commonly found in wild rice stands regardless of whether they are located in a river, lake, or cultivated field. Disease observation notes and anecdotal evidence (R. Nyvall, unpublished) suggest Fusarium head blight has been a common disease of wild rice since cultivation began. Although Fusarium head blight has not been reported on white rice (Oryzae sativa), Fusarium spp. have been reported to cause other diseases on this crop $(10,14)$. As examples, $F$. semitectum has been implicated in a necrosis that partially or totally covers the surface of white rice kernels and develops from flowering to ripening (14), and $F$. moniliforme has been reported to be commonly isolated from seed and implicated in the reduction of germination (4).

Fusarium head blight of small grains is caused by several Fusarium spp. and, in addition to causing direct losses through light weight grain, some of the causal organisms also have the potential to produce mycotoxins that are harmful to warm blooded animals, especially ruminants (16). As an alternative use, much of the harvested diseased small grain that exceeds FDA standards for mycotoxins is fed to livestock (ruminants) that are not affected by these toxins. However, most wild rice is used only for human food and is not used for livestock feed. Therefore, it was important to identify and elucidate the symptoms of Fusarium head blight on wild rice and to determine if mycotoxins were present in the processed seed sold directly in the food store.

Symptoms of Fusarium head blight on wild rice tend to be similar to those on other small grains. However, symptomatic grain tends to be eliminated before processing either through shattering or during harvest and is infrequently noticed. A relatively small percentage of symptomless seed also yielded Fusarium spp. and may potentially represent a health threat if consumed by humans. Symptomless seed may result when seed is infected too late in its development to produce typical Fusarium head blight symptoms, mature seed is saprophytically colonized, or a percentage of seed becomes infected, then diseased, without displaying typical symptoms of Fusarium head blight.

For the following reasons, there is little likelihood that most wild rice seed displaying Fusarium head blight symptoms will be consumed by humans. First, seed is infected early in its development by Fusarium spp., as indicated by the high percentage of diseased seed at the milk stage. However, most of this diseased seed shatters before the dough stage and continues to shatter until only a relatively small percentage of diseased ripe seed remains attached to the plant.

Second, diseased seed is lighter weight than healthy seed and is passed or blown through the harvest machine. Symptomatic seeds were easily observed in chaff that passed through combines, but symptoms were rarely observed in seed that was to be processed.
Lastly, it is unlikely that Fusarium spp. can survive the high temperatures (117 to $120^{\circ} \mathrm{C}$ for $30 \mathrm{~min}$ ) attained during processing. The isolation of $F$. graminearum at a very low incidence from processed wild rice purchased from a food store was possibly related to contamination by the fungus after processing.

$F$. graminearum was the species most frequently isolated from diseased kernels, similar to Fusarium head blight of other small grains caused by Fusarium spp. (10). Additionally, other Fusarium spp. were isolated that have been previously reported on wheat, with the exception of $F$. anthophilum, F. camptoceras, and F. solani (10). To our knowledge, these species are reported for the first time to be associated with symptoms of Fusarium head blight on small grains. However, this association remains circumstantial since these species were not tested for Koch's postulates. F. acuminatum, F. camptoceras, F. culmorum, F. semitectum, and $F$. solani were infrequently isolated. Therefore, the presence of these fungi could be due to saprophytic colonization of kernels and not to pathogenicity.

F. anthophilum, however, was frequently isolated from diseased seed in some fields but has not been previously reported as a causal agent of Fusarium head blight on other small grains (10). This may be due, in part, to past confusion surrounding the identification of Fusarium spp. As an example, $F$. anthophilum and $F$. subglutinans are similar taxonomically but separated on the basis of pear-shaped microconidia pro-

Table 3. Effect of seed source and storage conditions on isolation of Fusarium spp. from whole seed

\begin{tabular}{|c|c|c|c|}
\hline \multirow[b]{2}{*}{ Source ${ }^{y}$} & \multicolumn{2}{|c|}{ Storage $^{\mathrm{x}}$} & \multirow[b]{2}{*}{ Fusarium spp. $(\%)^{\mathrm{z}}$} \\
\hline & Temp (C) & Immersed (+) or not (-) & \\
\hline \multirow[t]{4}{*}{ Cultivated } & -20 & - & $46 \mathrm{a}$ \\
\hline & -20 & + & $12 \mathrm{~b}$ \\
\hline & 4 & - & $81 \mathrm{a}$ \\
\hline & 4 & + & $0 \mathrm{c}$ \\
\hline \multirow[t]{4}{*}{ Natural } & -20 & - & $51 \mathrm{a}$ \\
\hline & -20 & + & $14 \mathrm{~b}$ \\
\hline & 4 & - & $64 \mathrm{a}$ \\
\hline & 4 & + & $0 \mathrm{c}$ \\
\hline
\end{tabular}

x Seed was dried to 20 to $21 \%$ moisture for 2 to 3 days at 21 to $24^{\circ} \mathrm{C}$ then stored at either $-20^{\circ} \mathrm{C}$ or $4{ }^{\circ} \mathrm{C}$ and immersed or not in water for 5 months.

y Natural seed was obtained from Dora Lake in north central Minnesota. Cultivated seed was obtained from a cultivated wild rice paddy near Clearbrook in north central Minnesota.

${ }^{\mathrm{z}}$ Based on 1,000 seeds per sample. Ratings followed by the same letter are not significantly different $(P=0.05)$.

Table 4. Effect of storage temperature on isolation of Fusarium spp. from the caryopsis, palea and lemma, and whole wild rice seed gathered from a natural and a cultivated source ${ }^{\mathrm{x}}$

\begin{tabular}{|c|c|c|c|c|}
\hline Seed source ${ }^{y}$ & Temperature (C) & Whole seed $(\%)^{z}$ & Palea and lemma $(\%)^{\mathrm{z}}$ & Caryopsis $(\%)^{\mathrm{z}}$ \\
\hline \multirow[t]{2}{*}{ Natural } & -20 & $51 \mathrm{a}$ & $28 \mathrm{~b}$ & $4 \mathrm{c}$ \\
\hline & 4 & $64 \mathrm{a}$ & $36 \mathrm{~b}$ & $28 \mathrm{~b}$ \\
\hline \multirow[t]{2}{*}{ Cultivated } & -20 & $46 \mathrm{a}$ & $24 \mathrm{~b}$ & $3 c$ \\
\hline & 4 & $61 \mathrm{a}$ & $60 \mathrm{a}$ & $66 \mathrm{a}$ \\
\hline
\end{tabular}

x Seed was dried to 20 to $21 \%$ moisture for 2 to 3 days at 21 to $24^{\circ} \mathrm{C}$ then stored for 5 months.

y Natural seed was obtained from Moose River in north central Minnesota. Cultivated seed was obtained from a cultivated wild rice paddy near Clearbrook in north central Minnesota.

${ }^{z}$ Percentages are based on isolations from 300 whole seeds, 100 palea and lemma, and 100 caryopsis. Ratings followed by the same letter are not significantly different $(P=0.05)$. 
duced by $F$. anthophilum, according to Nelson et al. (9). However, F. subglutinans is separated taxonomically from $F$. moniliforme by bearing microconidia on polyphialides only in false heads and not on microconidial chains, whereas $F$. moniliforme bears microconidia both in false heads and in long chains. F. solani is identified on the basis of the presence of chlamydospores and long microconidiophores. This fungus tends to be more commonly associated with root and stem diseases and some cultures bear a superficial resemblance to $F$. anthophilum and F. subglutinans.

Seed from natural stands became diseased at the same growth stage as seed from cultivated fields. However, it is presumed that environmental conditions favorable for disease need to be present for a shorter time in cultivated fields than in natural stands. Seed from a natural stand is normally at different stages of maturity because of the different maturities of plants within the stand. In contrast, plants grown in a cultivated field are generally uniform in their growth stages. Therefore, because plants in a natural stand mature over a longer period of time, there must be a continuous source of inoculum, either from primary or secondary sources, and conducive environmental conditions for disease development over a longer period of time than for cultivated wild rice plants. In our experiment comparing infection at different growth stages of seed from natural stands and seed from cultivated fields, the percentages of infected seed at milk and dough growth stages were low; however, the trend of a small percentage of infected ripe seed remaining attached to the plant was consistent with previous experiments. Again, this likely indicates that most diseased seeds shatter and only a small percentage of such seeds remain attached to the plant, regardless of whether seed originates from a natural stand or cultivated field.

Fusarium spp. appear to effectively penetrate the entire seed and, with slight variations by different species, are not in one seed structure more than another. $F$. anthophilum was isolated more frequently from the outside of the seed, consisting of the palea and lemma, than from the caryopsis. Therefore, this may imply $F$. anthophilum does not penetrate into the seed in a manner similar to that of $F$. graminearum. A higher percentage of total Fusarium spp. was isolated from the palea and lemma than from the caryopsis. However, this may be due to an interruption, caused by our isolations, of fungal growth from the outer portion of the seed into the caryopsis. Had growth continued uninterrupted over a longer period of time, the incidence of Fusarium spp. isolated from the palea and lemma and from the caryopsis may have been similar.

The percentage of Fusarium spp. isolated from the palea and lemma of seed from the natural source was significantly higher than from the caryopsis. This difference was not detected in seed from the cultivated field. Therefore, this result may imply the caryopsis of seed from natural stands is less frequently infected than that from cultivated stands and, therefore, Fusarium head blight is less a problem in natural than in cultivated stands. However, further evidence will have to be obtained to support this conclusion.

The toxins nivalenol and deoxynivalenol were isolated from three fungal isolates obtained from seed from three different geographical sources. This is the first report of nivalenol and deoxynivalenol being produced by $F$. graminearum other than in Japan and Europe. However, no toxins were detected in the seed from which the isolates were obtained. Therefore, similar cautions used in placing other small grains in the human food chain may not have to be exercised with wild rice, based on these findings.

It is not certain where the source of primary inoculum for Fusarium spp. is, but it is presumed to originate from grasses and nearby small grain fields. Fusarium spp. do not survive in diseased seed that fall to the soil surface and are submerged in water when the field is flooded. Fusarium spp. were isolated from diseased seed submerged in water that was immediately frozen. However, when seed and water were thawed, no Fusarium spp. were isolated after 14 days. This indicates any seed that underwent submersion in water was not likely to be a source of inoculum. Normally, wild rice fields in Minnesota are flooded either in the autumn or in the spring, depending upon the water supply. Fusarium spp. were readily isolated from grasses growing on the field dikes and from residue in small grain fields located within $5 \mathrm{~km}$ of cultivated wild rice fields (R. Nyvall, unpublished).

$F$. graminearum was the only species tested for Koch's postulates. Seed was easily infected and became diseased when plants were inoculated at the early flowering stage, verifying $F$. graminearum as a cause of Fusarium head blight on cultivated wild rice.
ACKNOWLEDGMENTS

We wish to thank Laura Wagner and Christine Neary for technical assistance, and Ann Arendt and Leslie Johnson in the preparation of this manuscript. This research was supported in part by funding from the Minnesota Cultivated Wild Rice Council and the Agricultural Utilization Research Institute.

\section{LITERATURE CITED}

1. Barnett, H. L. 1960. Illustrated Genera of Imperfect Fungi. 2nd ed. Burgess, Minneapolis.

2. Bean, G. A., and Schwartz, R. 1961. A severe epidemic of Helminthosporium brown spot disease on cultivated wild rice in Minnesota. Plant Dis. Rep. 45:901.

3. Beattie, S., Schwartz, P. B., Horsley, R., and Casper, H. H. 1998. The effect of grain storage conditions on the viability of Fusarium and deoxynivalenol production in infested malting barley. J. Food Prot. 61:103-106.

4. Imolehin, E. D. 1983. Rice seedborne fungi and their effect on seed germination. Plant Dis. 67:1334-1336.

5. Johnson, D. R., and Percich, J. A. 1992. Wild rice domestication, fungal brown spot disease, and the future of commercial production in Minnesota. Plant Dis. 76:1193-1198.

6. Kohls, C. L., and Percich, J. A. 1984. Epidemiology and yield losses associated with fungal brown spot of wild rice. (Abstr.) Phytopathology 74:809.

7. Kohls, C. L., Percich, J. A., and Huot, C. M 1987. Wild rice yield losses associated with growth-stage-specific fungal brown spot epidemics. Plant Dis. 71:419-422.

8. McMullen, M., Jones, R., and Gallenberg, D. 1997. Scab of wheat and barley: A reemerging disease of devastating impact. Plant Dis. 81:1340-1348.

9. Nelson, P. E., Tousson, T. A., and Marasas, W. F. O. 1983. Fusarium Species: An Illustrated Manual for Identification. The Pennsylvania State University Press, University Park.

10. Nyvall, R. F. Field Crop Diseases. 3rd ed. Iowa State University Press, Ames. (In press.)

11. Nyvall, R. F., Percich, J. A., and Branter, J. R. 1994. Fungal brown spot of cultivated wild rice is two different diseases. (Abstr.) Phytopathology 84:1102.

12. Nyvall, R. F., Percich, J. A., Porter, R. A., and Brantner, J. R. 1995. Comparison of fungal brown spot severity to incidence of seedborne Bipolaris oryzae and B. sorokiniana and infected floral sites on cultivated wild rice. Plant Dis. 79:249-250.

13. Nyvall, R. F., Porter, R. A., and Percich, J. A. 1995. First report of scab on cultivated wild rice in Minnesota. Plant Dis. 79:82.

14. Ou, S. H. 1986. Rice Diseases. 2nd ed. Commonwealth Mycological Institute, Kew, Surrey, England. Eastern Press, London.

15. Percich, J., Zeyen, R., Huot, C. M., and Johnson, D. 1988. Wild rice growth stage scale. Pages 56-64 in: Minnesota Wild Rice Research 1987. Agric. Exp. Stn. Misc. Pub. 541988.

16. Wiese, M. V. 1987. Compendium of Wheat Diseases, 2nd ed. American Phytopathological Society, St. Paul, MN. 